\title{
Effect of Micro Arc Oxidation Treatment Time on In-Vitro Corrosion Characteristics of Titania Films on Cp Ti.
}

\author{
K. Venkateswarlu, J. Hari, D. Sreekanth, M. Sandhyarani, A. C. Bose, and N. Rameshbabu
}

\begin{abstract}
The present work is aimed at the optimisation of treatment time for the development of an oxide film on commercially pure titanium $(\mathrm{Cp} \mathrm{Ti})$ implant material by micro arc oxidation (MAO) process, to improve its corrosion resistance under $7.4 \mathrm{pH}$ simulated body fluid physiological conditions. The MAO treatments were conducted for 4,8 and 12 min in constant current mode by a DC power supply unit with an aqueous electrolyte solution comprising $15 \mathrm{~g} / \mathrm{l}$ of tri-sodium ortho phosphate $\left(\mathrm{Na}_{3} \mathrm{PO}_{4} \cdot 12 \mathrm{H}_{2} \mathrm{O}\right)$. The phase composition of the fabricated films was analyzed by X-ray diffraction (XRD) technique. The morphology and thickness of the films were determined by scanning electron microscopy (SEM) and the corrosion characteristics were assessed by potentiodynamic polarization technique. The XRD results demonstrated that the oxide films mainly consisted of anatase phase. While the average size of isolated surface pores was in the range of 0.5 to $5 \mu \mathrm{m}$, the thickness of the film varied from 24 to $55 \mu \mathrm{m}$. A significant improvement in the corrosion resistance was observed for the MAO treated Cp Ti implant material compared to that of the untreated. The surface pore features, the thickness of the film and the corrosion characteristics of the developed films were correlated with the MAO treatment time. Of the three different MAO treatment times employed in the present study, $8 \mathrm{~min}$ treatment time was established to be an optimized one for developing oxide films on $\mathrm{Cp}$ Ti to provide an optimal surface porosity and to minimise corrosion rate under physiological conditions.
\end{abstract}

Index Terms-Cp $\mathrm{Ti}$, micro arc oxidation, $\mathrm{TiO}_{2}$, electrochemical corrosion, biomedical applications.

\section{INTRODUCTION}

Titanium (Ti) and its alloys are extensively used for biomedical applications, especially for bone-anchoring systems, such as dental and orthopedic implants [1]. They have excellent bulk mechanical and passive surface properties such as low modulus of elasticity, high strength to weight ratio and good corrosion resistance. The good corrosion resistance of titanium is due to the very stable and tenaciously adherent

Manuscript received July 24, 2012; revised October 23, 2012.

K. Venkateswarlu is with the Department of Physics and Department of Metallurgical and Materials Engineering, National Institute of Technology, Tiruchirappalli, 620015, Tamil Nadu, India (e-mail: kotharu.venkat@ gmail.com).

J. Hari is with the Department of Prosthodontics, J. K. K Nataraja Dental College and Hospital, Komarapalayam, Namakkal, 638183, Tamil Nadu, India (e-mail: jangalahari@gmail.com).

A. C. Bose is with the Department of Physics, National Institute of Technology, Tiruchirappalli, 620015, Tamil Nadu, India (e-mail: acbose@nitt.edu).

D. Sreekanth, M. Sandhyarani, and N. Rameshbabu are with the Department of Metallurgical and Materials Engineering, National Institute of Technology, Tiruchirappalli, 620015, Tamil Nadu, India (e-mail: sreekanth54@gmail.com, muthyala07@gmail.com, vmuthu@nitt.edu and rameshrohitht@gmail.com). oxide film spontaneously formed over its surface. However, the titanium oxide film that grows spontaneously in many aqueous environments or in air has only a thickness of a few tens of nanometrers [2]. This naturally formed thin oxide layer can be lost soon due to wear, when these materials are implanted for load bearing applications. This results in an increase of corrosion rate and a decrease of biological performance and in turn reduces the efficiency and service time of the implant material [3].

It was found that developing a thick, micro porous and nanocrystalline oxide film on $\mathrm{Ti}$ and its alloys by surface modification techniques improved their biological performance and corrosion resistance [4].

Micro arc oxidation (MAO) which is also known as Plasma electrolytic oxidation (PEO) and anodic spark oxidation (ASO) is a recent technique which can produce a porous, relatively rough and firmly adherent titanium oxide film on $\mathrm{Ti}$ based substrates [5], [6].

A number of studies have been performed addressing the role of MAO process parameters on various properties of the films. It is reported that the treatment time is an important MAO process parameter and is found to strongly influence the film properties, such as the crystalline content of the phases, compactness, film thickness, hardness and the corrosion resistance of the film [7].

Keeping the importance of the process time in mind, the present study is focused on establishing an optimized treatment time for the development of an oxide film on $\mathrm{Cp} \mathrm{Ti}$ implant material by $\mathrm{MAO}$ process, in order to improve its corrosion resistance under $7.4 \mathrm{pH}$ simulated body fluid (SBF) physiological conditions.

\section{MATERIALS AND METHODS}

\section{A. Sample Preparation}

The Cp Ti test coupons with dimensions of $20 \times 15 \times 1.5$ $(\mathrm{mm})^{3}$ were abraded down to 1000 grit emery paper and then ultrasonically cleaned in alcohol, acetone and distilled water for 5 min successively before use. Prior to MAO treatment, acid activation was performed for $30 \mathrm{~s}$ in a diluted mixture of nitric acid and hydrofluoric acid to remove the natural titanium oxide layer and surface contaminants. The MAO experiments were conducted for 4, 8 and $12 \mathrm{~min}$ in an aqueous electrolyte solution comprising $15 \mathrm{~g} / \mathrm{l}$ of tri-sodium orthophosphate (TSOP, $\mathrm{Na}_{3} \mathrm{PO}_{4} \cdot 12 \mathrm{H}_{2} \mathrm{O}$ ). A stainless steel bowl of $15 \mathrm{~cm}$ diameter containing the electrolyte system was used as cathode and the test coupons were immersed as anode. A DC power supply unit with a maximum peak voltage of 500 
$\mathrm{V}$ and a maximum output current of $5 \mathrm{~A}$ was employed to carry out the process. The coating process was carried out at a constant current of 0.55 A corresponding to a current density of about $50 \mathrm{~mA} / \mathrm{cm}^{2}$ at the work piece. During the process the electrolyte bath temperature was maintained around $40{ }^{\circ} \mathrm{C}$. After the MAO treatment, the samples were cleaned with distilled water and air dried at room temperature. The samples treated for 4, 8 and 12 min are respectively labelled as S1, S2 and S3. The untreated sample (Cp Ti substrate) is referred to as "S"

\section{B. Structural and Morphological Studies}

The phase composition of the films was analyzed by Rigaku X-ray diffractometer (UltimaIII, Rigaku, Japan) using $\mathrm{Cu} \mathrm{K} \alpha$ radiation at $40 \mathrm{KV}$ and $30 \mathrm{~mA}$ with a scan speed of $1 \%$ min and a step size of $0.05^{\circ}$. The average crystallite size and mass fractions of the oxide phases were determined by Scherer equation and Spur formula, respectively and the results are listed in Table I. Scherer equation to calculate crystalline size is given as

$$
D=\frac{0.9 \lambda}{\beta \cos \theta}
$$

where $\lambda$ is the $\mathrm{X}$ - ray wave length, $\theta$ be the Bragg angle and $\beta$ is the full width at half maximum. The mass fraction of rutile was calculated by the formula [8], which is the relationship between intensities of anatase (101) and rutile (110) peaks

$$
X_{R}=\frac{1}{1+0.8\left(I_{A} / I_{R}\right)}
$$

where $I_{A}$ and $I_{R}$ are the characteristic peak intensities of anatase (101) and rutile (110) peaks respectively.

The surface morphology and the thickness of the films were observed using a scanning electron microscope $(\mathrm{S} 3000 \mathrm{H}$, Hitachi, Japan). At a number of randomly selected locations, the scanned regions were photographed and these micrographs were subjected to image analysis to measure the discharge channels size. To measure the thickness of the film one edge of the test sample was well polished and cleaned ultrasonically in ethanol and acetone and then subjected to SEM cross section analysis. The measured thickness values for $S 1, S 2$ and $S 3$ are reported in Table I.

\section{In-Vitro Corrosion Characteristics}

The potentiodynamic polarization studies on S, S1, S2 and S3 samples were carried out under simulated body fluid conditions $\left(37^{\circ} \mathrm{C}\right.$ and $\left.7.4 \mathrm{pH}\right)$. The SBF test medium of $\mathrm{pH}$ 7.4 was prepared following the procedure suggested by Kokubo et al. [9]. Potentiodynamic polarization plots were obtained using ACM Gill AC corrosion testing unit to evaluate the corrosion behaviour of the untreated and MAO treated samples. A three electrode cell, with sample as working electrode, saturated calomel electrode (SCE) as reference electrode and platinum foil as counter electrode, was employed in this test. During the anodic polarization scan, the sample with an exposed area of $0.5 \mathrm{~cm}^{2}$ was kept in contact with the solution and then polarized from cathodic to anodic region at a scan rate of $60 \mathrm{mV} / \mathrm{min}$ in the range of -500 $\mathrm{mV}$ to $3000 \mathrm{mV}$ with reference to SCE. From the polarization curve, the corrosion current density $\left(j_{\text {corr }}\right)$ was determined by
Tafel extrapolation method.

\section{RESULTS AND DISCUSSION}

\section{A. Structural Characteristics of the MAO Films}

The XRD patterns of S, S1, S2 and S3 samples are shown in Fig. 1.

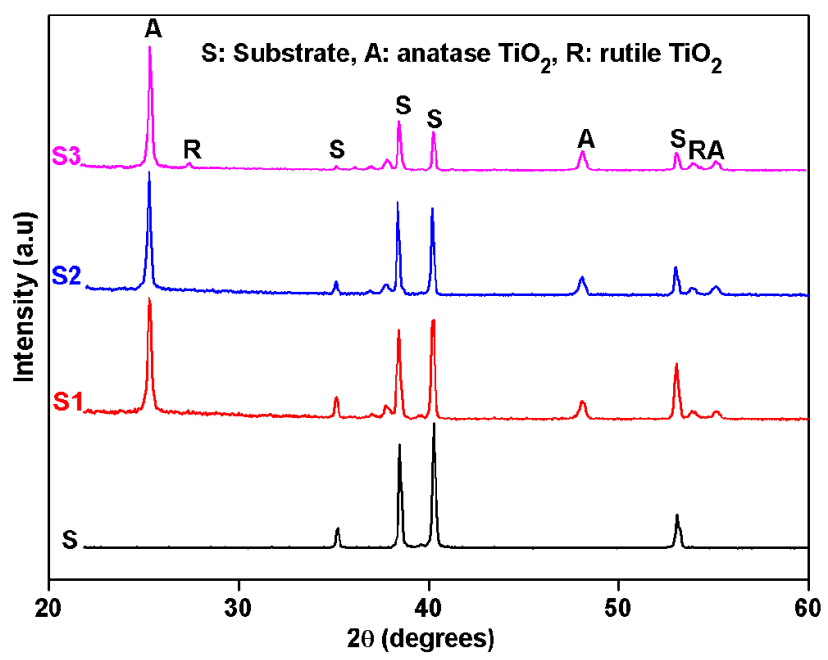

Fig. 1. XRD patterns of $S, S 1, S 2$ and $S 3$ samples.

It shows that while the $S 1$ and $S 2$ oxide films exhibit only the characteristic diffraction peaks of anatase phase (at $2 \theta \approx 25.3^{\circ}$, JCPDS No: 21-1272), the $S 3$ film shows an additional diffraction peak (at $2 \theta \approx 27.7^{\circ}$, JCPDS No: $21-1276$ ) corresponding to rutile phase. The appearance of rutile phase $(\approx 9 \mathrm{wt} \%)$ in $S 3$ sample indicates that the temperature in the MAO discharge channels is very high enough to take the phase transformation from metastable anatase phase to thermodynamically stable rutile phase. This suggests that prolonged MAO treatment time results in the liberation of more thermal energy that contributes to the anatase to rutile phase transformation. This can be evidenced by the relatively high film forming voltages and rise in temperature of electrolyte solution observed during the treatment. In other words, as the MAO process continues, the film thickness increases and accordingly the applied voltage also needs to be increased to reach the dielectric breakdown strength of already grown oxide film. Thus, prolonged MAO process is associated with higher processing voltages which lead to higher sparking energy. The formation of an initial anatase phase and subsequent transformation to rutile phase is presented in detail in authors' previous work [8]. It can be noticed from Fig. 1 that, for the samples $S 1, S 2$ and $S 3$, there is a decrease in the intensities of the substrate diffraction peaks indexed by the letter 's' suggesting that the developed oxide films could prevent the incident X-ray beam from reaching the substrate. The sudden fall, from $S 2$ to $S 3$, in the intensity of the substrate diffraction peaks can be attributed to the rapid increase in the film thickness from 8 min to 12 min treatment time which is evidenced by the measured thickness values reported in Table I. Further, the crystallite size of the anatase phase structure in the direction perpendicular to (101) plane is 37,41 and $44 \mathrm{~nm}$ respectively for $S 1, S 2$ and $S 3$. This shows that prolonged $\mathrm{MAO}$ process enhances the crystalline growth 
which is due to the higher sintering effect that may come from higher sparking energy.

\section{B. Morphological Characteristics}

The surface morphologies of $S 1, S 2$ and $S 3$ MAO films are shown in Fig. 2. It can be seen from Fig. 2 that all the MAO films exhibited a porous structure which is the characteristic of the films grown by MAO process. In fact, during the MAO process, the film formation and growth take place as follows. Initially, numerous discrete micro arc discharge channels are formed on the anodic surface. Because of the high temperature in the discharge channels, titanium is melted out of the substrate and participates in the plasma chemical reactions to form the oxidation products. When the oxidation products are ejected out of the micro arc discharge channel, they leave a pore (dark circular spot) on the film surface. Thus, the MAO films usually show a porous surface structure [10]. In the next step of the MAO process, the ejected oxidation product will come in contact with the surrounding electrolyte, gets quenched and finally deposited over the surface of the already grown film and the thickness of the film increases in that location. Thus, as the MAO process continues, the existing pores will be covered by the newly depositing oxidation products as shown by the black circles in Fig. 2 . However, the surface pore characteristics (number and size) are strongly affected by the MAO process parameters such as treatment time [11], [12]. It can be observed from Fig. 2 that while the surface of $\mathrm{S} 1$ exhibited comparatively more number of uniformly distributed pores with sizes of major pores ranging from $0.5 \mu \mathrm{m}$ to $4 \mu \mathrm{m}$, the surface of $S 3$ showed less number of pores which are discharge channels open to the film surface. Further, the $S 3$ film showed canal-like network structure with thicker crater walls which is indicative of higher film thickness compared to $S 1$ and $S 2$. On the other hand the surface pore features (number and size) of $S 2$ film falls in between to that of $S 1$ and $S 3$ films. Thus the different surface morphologies of the films fabricated for different treatment times may be related to the dissimilar characteristics of the micro-sparks, such as size and number of sparks occurring during the MAO process. The decrease in pore density and increase in pore size from $S 1$ to $S 3$ is explained as follows: as the MAO treatment time increases, the film thickness increases. Basically, in a thicker film, higher energy is required for the current to pass through the film. Under this condition, the current is localized at weak points of the film formed to find its way through the film. This is the reason why the number of sparks decreases but their size increases as the film gets thicker. In fact, an increase in diameter of the discharge channels is the way how the process compensates the reduction in number of the channels [11], [13]. Hence, the size and the number of sparks are affected by the thickness of the film. The higher thickness of the sample $S 3$ treated for $12 \mathrm{~min}$ is also evidenced by the presence of thick walled regions that are rapidly solidified around the circular discharge channels. Further the $S 3$ sample shows thermal stresses driven micro cracks, shown by the arrow symbol in Fig. 2, resulting from the rapid quenching of the oxidation products. Thus the process treatment time played a significant role on the surface pore characteristics of the samples.

\section{Potentiodynamic Polarization Studies}

The passivation behaviour of the substrate and the MAO films was studied by conducting potentiodynamic polarization (PDP) tests. Fig. 3 depicts the PDP curves of the substrate and the MAO films obtained over a potential range of $-500 \mathrm{mV}$ to $3000 \mathrm{mV}$ Vs SCE. It can be observed that all the tested samples exhibit mainly two regions in their anodic sections, namely the active region at lower anodic potentials and the passive region at comparatively higher anodic potentials. In addition, for the substrate ' $S$ ' a trans-passive region at a positive potential of about $1400 \mathrm{mV}$ Vs SCE can be observed as shown in Fig. 3. The maximum current densities $\left(j_{\text {active }}\right)$ of all the test samples attained in their respective active regions is found to decrease in the order $S>S 1>S 3>S 2$, which can be attributed to the variations in the rate of metal oxidation process.
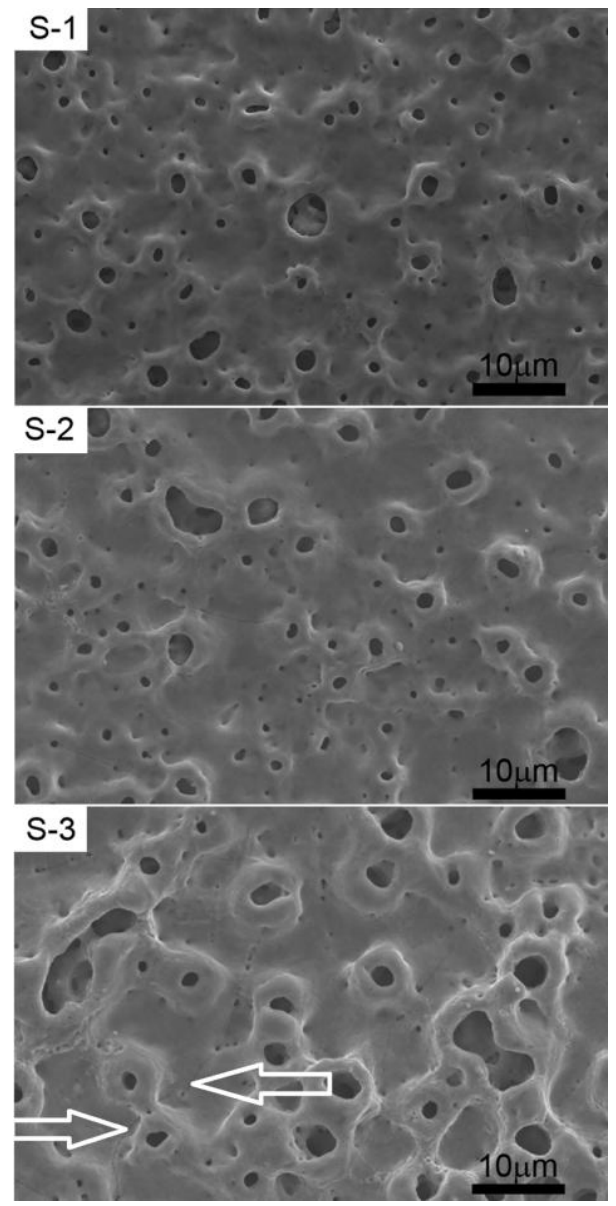

Fig. 2. SEM surface micrographs of $S 1, S 2$ and $S 3$ samples

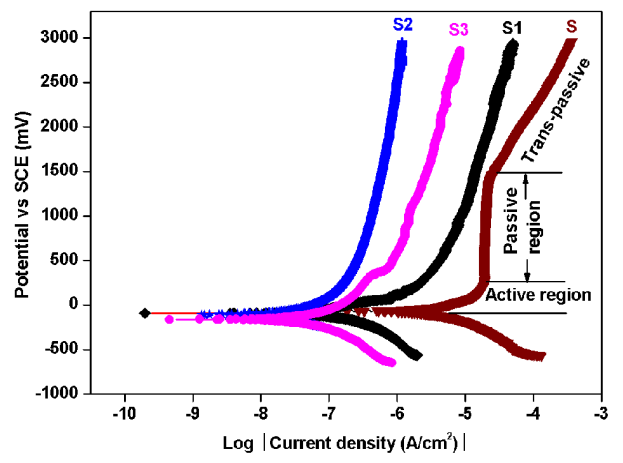

Fig. 3. Potentiodynamic polarization curves of S, S1, S2 and S3 samples in SBF physiological conditions.

In fact, the rate of metal oxidation at the metal/oxide 
interface is strongly influenced by the rate of diffusion of corrosive ions towards the interface and the rate of metal ion transfer away from the metal surface which is further controlled by the resistance offered by the surface oxide film. Thus among the MAO films, the observed least $j_{\text {active }}$ of $S 2$ film can be attributed to its highest resistance offered to the diffusion of ionic species due to mainly its less porous and less defective structure. Similarly, the observed highest $j_{\text {active }}$ of $S 3$ film can be attributed to mainly its defective structure as evidenced by the surface cracks of the $S 3$ film shown in Fig. 2 . It can also be observed that the anodic current density of the substrate is virtually independent of the sweep potential in the passive region (shown in Fig. 3) which is mainly due to the formation and thickening of a protective oxide layer over its surface. Further, the sudden increase of current density in the trans-passive region is due to the breakdown of the formed protective film and / or due to the evolution of oxygen at sufficiently higher positive potentials. On the other hand, the
PDP curves of all the MAO treated samples exhibited nearly similar behaviour at higher anodic potentials namely the anodic current densities of the films increases gradually with the increase in applied potential. However, the anodic current density of $S 2$ film is significantly lower than that of all other MAO films and substrate, presumably due to the controlled electrochemical reactions over its surface. It can also be noticed from Fig. 3, that the potentiodynamic polarization curves of all the MAO films have not shown any breakdown indicating that they remain passive almost over the entire range of the applied potential. In summary, the passivation tendency of all the samples is found to decrease in the order $S 2>S 3>S 1>S$ indicating that the sample treated for $8 \mathrm{~min}$ shows comparatively better corrosion resistance. Hence $8 \mathrm{~min}$ treatment time is found to be an optimized one for developing a film with better corrosion resistance in $7.4 \mathrm{pH}$ physiological conditions.

TABLE I: THE IDENTIFICATION CODES, XRD, SEM CROSS SECTION AND CORROSION STUdy RESULTS OF THE MAO TREATED SAMPLES

\begin{tabular}{|c|c|c|c|c|c|c|}
\hline \multirow{2}{*}{ Sample code } & \multirow{2}{*}{$\begin{array}{l}\text { Treatment time } \\
\text { (min) }\end{array}$} & \multicolumn{2}{|c|}{ Phase composition (wt \%) } & \multirow{2}{*}{$\begin{array}{c}\text { Crystallite size }( \pm 1 \\
\mathrm{nm})\end{array}$} & \multirow{2}{*}{$\begin{array}{c}\text { Film Thickness } \\
(\mu \mathrm{m})\end{array}$} & \multirow{2}{*}{$\mathrm{j}_{\mathrm{corr}}\left(\mu \mathrm{A} / \mathrm{cm}^{2}\right)$} \\
\hline & & Anatase & Rutile & & & \\
\hline S & - & - & - & - & - & 2.80 \\
\hline S1 & 4 & 100 & - & 37 & 24 & 0.63 \\
\hline S2 & 8 & 100 & - & 41 & 36 & 0.05 \\
\hline S3 & 12 & 91 & 9 & 44 & 55 & 0.09 \\
\hline
\end{tabular}

\section{CONCLUSION}

MAO process was successfully employed to fabricate titania films on $\mathrm{Cp} \mathrm{Ti}$ in an aqueous solution comprising of TSOP under constant current mode using a DC power supply unit. The thickness of the film increases from 24-55 $\mu \mathrm{m}$ and the average crystallite size of the anatase phase structure increases from $37 \mathrm{~nm}$ to $44 \mathrm{~nm}$ with the increase of processing time from $4 \mathrm{~min}$ to $12 \mathrm{~min}$. All the MAO films showed a significant improvement in the corrosion resistance compared to that of substrate. However, the film grown for $12 \mathrm{~min}$ sample exhibits thermal stress derived cracks over its surface and consequently showed inferior corrosion resistance compared to that of the film grown for $8 \mathrm{~min}$. The film grown for $8 \mathrm{~min}$ processing time is found to be an optimized one and showed better corrosion resistance among all the samples under study.

\section{ACKNOWLEDGEMENT}

The authors would like to acknowledge the grants from Department of Biotechnology, New Delhi (BT/PR-11731/MED/32/99/2008, dated 19-08-2009).

\section{REFERENCES}

[1] K. Bordji, J. Y. Jouzeau, D. Mainard, E. Payan, P. Netter, K. T. Rie, T. Stucky, and M. H. Ali, "Cytocompatibility of Ti-6Al-4V and Ti-5Al-2.5Fe alloys according to three surface treatments, using human fibroblasts and osteoblasts," Biomaterials, vol. 17, pp. 929-940, 1996.
[2] W. Xue, C. Wang, R. Chen, and Z. Deng, "Structure and properties characterization of ceramic coatings produced on Ti-6Al-4V alloy by microarc oxidation in aluminate solution," Mater. Lett., vol. 52, pp. 435-441, 2002.

[3] K. Venkateswarlu, S. Suresh, N. Rameshbabu, A. C. Bose, and S Subramanian, "Effect of electrolyte chemistry on the structural, morphological and corrosion characteristics of titania films developed on Ti-6Al-4V implant material by plasma electrolytic oxidation," Key Eng. Mater., vol. 493-494, pp. 436-441, 2012.

[4] X. Liu, P. K. Chu, and C. Ding, "Surface modification of titanium, titanium alloys, and related materials for biomedical applications," Mater. Sci. Eng. R, vol. 47, pp. 49-121, 2004.

[5] Y. Han and K. Xu, "Photoexcited formation of bone apatite-like coatings on micro-arc oxidized titanium," J. Biomed. Mater. Res., vol. 71A, pp. 608-614, 2004.

[6] W. H. Song, Y. K. Jun, Y. Han, and S. H Hong, "Biomimetic apatite coatings on micro-arc oxidized titania," Biomaterials, vol. 25, pp. 3341-3349, 2004

[7] W. Z. Dong, J. Z. Hua, Y. Z. Ping, and Z. X. Lin, "Influence of treatment time on structure and property of ceramic coatings formed on LY12 aluminum alloy by micro-arc oxidation," J. Inorg. Mater., vol. 22, no. 3, pp. 555-559, 2007.

[8] K. Venkateswarlu, N. Rameshbabu, D. Sreekanth, A. C. Bose, V. Muthupandi, N. K. Babu, and S. Subramanian, "Role of electrolyte additives on in-vitro electrochemical behaviour of micro arc oxidized titania films on Cp Ti,” Appl. Surf. Sci., vol. 258, pp. 6853-6863, 2012

[9] T. Kokubo and H. Takadama, "How useful is SBF in predicting in vivo bone bioactivity," Biomaterials, vol. 27, pp. 2907-2915, 2006.

[10] A. L. Yerokhin, V. V. Lyubimov, and R. V. Ashitkov, "Phase formation in ceramic coatings during plasma electrolytic oxidation of aluminium alloys," Ceram. Int., vol. 24, pp. 1-6, 1998.

[11] G. Sundararajan and L. R. Krishna, "Mechanisms underlying the formation of thick alumina coatings through the MAO coating technology," Surf. Coat. Technol., vol. 167, pp. 269-277, 2003.

[12] G. L. Yang, X. Y. Lu, Y. Z. Bai, H. F. Cui, and Z. S. Jin, "The effects of current density on the phase composition and microstructure properties 
of micro-arc oxidation coating," J. Alloys Compd., vol. 345, pp. 196-200, 2002

[13] A. Ghasemi, V. S. Raja, C. Blawert, W. Dietzel, and K. U. Kainer, "The role of anions in the formation and corrosion resistance of the plasma electrolytic oxidation coatings," Surf. Coat. Technol., vol. 204, pp. 1469-1478, 2010.

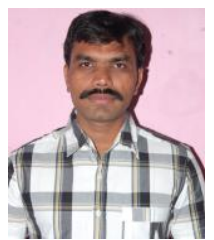

K. Venkateswarlu was born in Bayyavaram (Andhrapradesh, India) on $24^{\text {th }}$ July, 1984. He obtained his M.Tech. degree (2009) from the Department of Metallurgical and Materials Engineering and presently pursuing Ph.D. degree in the Department of Physics, National Institute of Technology, Tiruchirappalli, Tamil Nadu, India. His research interest is surface modification and characterization of biomaterials.

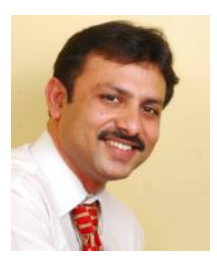

Jnagala Hari was born in Kadapa (Andhrapradesh, India) on $19^{\text {th }}$ January, 1975 . He obtained his master degree in Dental Surgery in 2009 from the Department of Prosthodontics and presently working as professor in the Department of Prosthodontics, J.K.K. Natarajan Dental college and hospital, Kommarapalem, Tamil Nadu, India. His research interests are surface modification of titanium dental implants and corrosion study of biomedical implant materials.

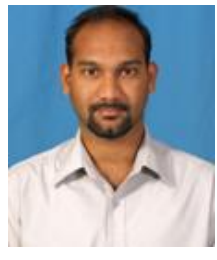

D. Sreekanth was born in Hyderabad (Andhrapradesh, India) on $4^{\text {th }}$ December, 1979. He obtained his M.Tech (2005) and presently pursuing Ph.D. degree in the Department of Metallurgical and Materials Engineering, National Institute of Technology, Tiruchirappalli, Tamil Nadu, India. His research interest is plasma electrolytic processing and corrosion study of biodegradable implant materials.

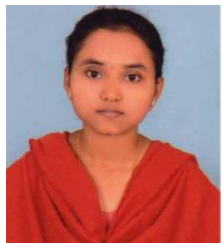

M. Sandhyarani was born in Vijayawada (Andhrapradesh, India) on $16^{\text {th }}$ July, 1984. She obtained her M.Tech. degree (2009) and presently pursuing Ph.D. degree in the Department of Metallurgical and Materials Engineering, National Institute of Technology, Tiruchirappalli, Tamil Nadu, India. Her research interest is plasma electrolytic oxidation treatment and corrosion study of biomedical

implant materials

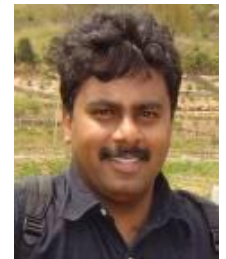

A. Chandra Bose is currently working as associate professor in the Department of Physics, National Institute of Technology, Tiruchirappalli, India. $\mathrm{He}$ is author of 65 scientific articles and 70 contributions to seminars and conferences. His current research interests are in the field of oxide nanomaterials for potential applications and microplasma for MEMS applications.

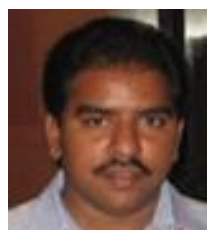

N. Rameshbabu obtained his Ph.D. degree from Indian Institute of Technology Madras, Tamil Nadu, India. $\mathrm{He}$ is currently working as assistant professor in the Department of Metallurgical and Materials Engineering, National Institute of Technology, Tiruchirappalli, India His research interests are in the field of advanced bioceramics, surface modification of metallic implants, nanostructured processing of materials. 